\title{
The Effect of Regulative Metacognition Strategies on Reading performance of Iranian Pre-intermediate Learners
}

\author{
Fatemeh SOBHANI, Parastoo BABASHAMSI
}

\begin{abstract}
Reading is one of the most important skills among all the other language skills. It helps the learner to achieve a lot of information and serves as a primary source of input, and consolidates their previous knowledge. The present study aimed at investigating the effect of regulative metacognition strategies on EFL learners' reading comprehension. A null hypothesis was proposed to answer the questions of this study: - There is no statistically significant relationship between regulative reading strategies and reading comprehension. To test this hypothesis, a sample of 126 pre- Intermediate students from an English Institution were chosen, which reduced to 77 by conducting a placement test as a proficiency test. Then they were randomly divided into two groups. The control group took placebo (usual performance) and experimental group took the treatment (regulative metacognition strategies). Before starting the study a pretest was conducted. After the treatment they administered a posttest to evaluate the significance of the treatment. Then the Independent $t$ - test was utilized, to analyze and evaluate the data from these two tests. Results revealed from this evaluation indicated that in post-test there is a significant difference between two groups, implying that regulative metacognition strategies had a positive effect on reading comprehension.
\end{abstract}

Keywords: metacognition, reading comprehension.

\section{Introduction}

Knowing English language is the most important element for academic, nonacademic studies, social development, and professional success all over the world. Teaching English language in foreign countries, can develop economic growth, expansion of technology, and applied science (Heilman 1998). So teaching and learning English language is very important in developing countries. He believed that people utilize English language for their communication and a large amount of reading material is written in this language. So, learners can gain information from the different fields of knowledge. None-native learners study language to get a certain level of proficiency and improve their comprehension in English text.

Flavell (1979) was the first one who created the theory of metacognition. He said, children will fail to generalize the learned strategies, if they are not aware of the metacognition. He believed, adults need more time to learn or remember harder words. Therefore, adults use their metamemory. Our metacognition allows us to utilize suitable strategies to deal effectively with the task demands. So, the role of meta-memory is completely different among children and adults. 
Lack of meta-memorial knowledge among children unable them to generalize mnemonic strategies.

Brown (1980) put emphasize on the serious role of metacognition in reading. But the concept of metacognition in reading is related to several years before those time. For example Huey (1968) believed that reading is a thought getting and thought manipulating. The scholars paid attention to the importance of active learning and active comprehension of what is read, and they did not focus attention on metacognitive procedures and the relationship between metacognition and strategy use.

\subsection{Metacognitive reading strategies}

Metacognitive reading strategies can be classified in three groups: planning, monitoring, and evaluating strategies (Israel, 2007). He stated that planning strategies are used before reading. For instance, students' background knowledge can be used for preparing them for reading. Learners easily can check their reading materials or text structure, like question and answer, cause and effect, and compare and contrast. Pressley stated that planning strategy means, set the goal for reading comprehension (2002).

Monitoring strategies can happen during reading. For example, self-questioning, vocabulary, summarizing and inferring the main idea of each paragraph (Israel, 2007; Pressley, 2002). Finding which part of the text can be emphasized or ignored based on the purpose of the text is monitoring strategy (Hudson, 2007). He believed that evaluating strategies occur after reading. It means when learners read the text and think about how to apply it to other situations. They may recognize with the author, a narrative, or main character, and have a better perception of the situation in the reading text.

Regulation of cognition is one of the most important strategies. It refers to active monitoring of cognitive procedures and the actual use of strategies employed (Flavell, 1979; Schraw, 1994).

One of the most important form of regulation of cognition is metacognitive monitoring, which is the active regulation and awareness of leaners' comprehension on a task (Butler \& Winne, 1998). The learners should find the relation between one's perspective and judgment of one's actual performance (Stone, 2000).

This study explored reading theories among EFL/ESL learners, especially reading practice from a theoretical framework of metacognition. Schwartz and Perfect (2002) believed that there are two kinds of foundation in metacognitive research. The first one is rooted in the study of Hart (1965), who explored feeling of knowing judgments, which emphasized on memory.

The second type originated in the study of Flavell (1976), an American development psychologist, influenced by Piaget, Flavell was interested how people manage the interplay of consciousness and the cognitive process. Reading for understanding and learning deeply needs more attention, information, encoding and retrieval than reading for enjoyment (Shih, 1992).

Reading is an internal, mental process that cannot be observed directly (Heilman, 1998).

Successful learners improve predictions about the content of a passage with textual clues. Awareness and experience help them to improve their expectation about what they will read (Silberstein, 1994). 
A successful reader always changes the rate of his reading. He skims the text for getting information and read carefully when he found it. He reads rapidly to make sure that he has understood it and takes a note if it is necessary. For finding the details and looking for a specific piece of information needs to read more slowly. The person, who does not know what he is looking for, may on one hand skip important details because he does not recognize their value and on the other hand, may keep brooding over minor details (Ahiya, 1993).

Ahiya (1993) stated that a combination of reading rate and reading comprehension gives an idea of the reading ability of the individual. Incidentally, university students seem to be wasting a lot of time because they are unable to decide which items of printed matter are going to be of most help to them by any other method than reading them all. Moreover, they are unable to apply reading speeds when they have to cover more materials in a short time. Furthermore, they are handicapped in applying reading skills. Studies have shown that the rate of reading can be improved with training.

Nowadays, learning strategy research is popular and even practical. But most learning strategies are limited to general strategies, particularly cognitive strategies. The metacognitive is the new field that is interesting for some researchers. Recently, metacognition has been found to be effective in second language teaching and learning. Developing metacognitive awareness in learners may also lead to the development of stronger cognitive skills and much deeper processing. In fact, metacognitive strategy is useful in daily life (Anderson, 2000).

Students, especially poor readers, need instruction in reading strategies, as metacognitive ones most scholars suggested it (e.g., Cohen, 1998; Gersten et al., 1997; Nunan, 1997; Pressley and El-Dinary, 1997; Swanson and De La Paz, 1998; Williams, 2000). The teachers can use some training to help learners to monitor their own learning. Cohen claimed, "Strategy training encourages students to find their own pathways to success, and thus it promotes learner autonomy and self-direction" (1998). As far as reading is concerned, reading strategy instruction may be (1) separate from reading, (2) fixed in reading, or (3) a mixture of the two. The challenges of knowledge explosion demand efficient readers. The pace at which knowledge is growing and changing is so rapid that much of the education given to students will go out of date within a couple of years. They will have to re-educate themselves to improve in their careers.

According to Ahiya (1993), "What can we teach students more useful other than the power of reading" (p.84). The ability to read well constitutes one of the most valuable skills a human being can acquire. Reading can be a crucial passage communication with an ever-widening word. In fact, we live in the world that living without reading is not possible. Reading has various determinations. It is necessary for everyday activities. It is essential for progress in school. It is needed for recreation and for many other purposes. The people need reading skill everywhere. Proficient reading infers specific comprehension of the communication presented in print or writing in a reasonably speeded form. Efficient reading has two main factors: Comprehension and rate of reading.

Given the fact that English is the dominant language of international communication and academia, Carrel claimed that reading is seen as an extremely complex activity involving a combination of perceptual, linguistics and cognitive abilities (1998). The ability to read and to comprehend in English is the most vital skill at secondary, pre-university and university levels. 
Students have to possess this ability because almost all references are in the English language. A student who is weak in the reading skills will not be able to extract enough information to perform satisfactorily in his studies. As Shih claimed most of the learners prefer to improve their reading skill for comprehension and learning, than enhance it for enjoyment or for getting some general information (1992).

Ahiya found that the reading comprehension among students at university level was not enough because most of the time they were reading legal documents. This problem is because of their non-flexible approach to the range of reading materials, which they encounter. They are very rigid in their approach to reading and never think of using different reading strategies according to the reading purpose and occasion (1993).

As Champeau believed, about 400 million people around the world use English as a second or foreign language. Their success or failure on their occupation may depend on their ability to read the latest scientific and technical publications in English (1997).

Most of the students around the world think, reading is the most important skill in a second language. They think reading is the main reason to learn the language. Thus, for at least three groups of students in contexts, for advance levels of proficiency and with a need for English for academic purposes, reading is a critical point in the learning language.

\subsubsection{Planning}

Planning includes the election of suitable strategies and distribution of resources that affect performance (Zare-ee, 2008). For example, guessing before reading, strategy sequencing, and giving time or devotion selectively before starting a task. So, forethought is another name of planning that is a process of thinking about and forming the activities required to reach an anticipated goal. The process of thinking is necessary to make and complete the plan, or mixing of it with other plans, that is, it chains predicting of development with the preparation of situation of how to react to them (Miller, 1985).

Metacognitive reading strategy can be categorized to three bunches: a) planning, b) monitoring, and c) evaluating (Israel, 2007; Pressley \& Afflerbach, 1995). Before reading learners can use planning strategies. For instance, learners can use background knowledge to get prepared for reading (Almasi, 2003; Israel, 2007). Also, learners can utilize previewing a title, picture, illustration, heading, or subheading to understand the outline of the script. They can preview the overall information in the text and the structure (Almasi, 2003; Paris, Wasik, \& Turner, 1991). Students can find that their reading material has a specific text structure, such as compare and contrast, cause and effect, and question and answer. So, set the goal for reading can be classified as a planning strategy (Paris et al., 1991; Pressley, 2002).

Planning strategy include the mixture of proper strategies and sharing of some resources that impact on performance. For example, before reading learners can predict and allocate the time or focus on some important sections when they are going to start the task. So, the process of thinking and forming the activities to achieve a desired goal is an example of planning strategy. This thought process is very important to make and complete the plan, or mix it with other plans (Zare-ee, 2008). 


\subsubsection{Monitoring}

This strategy is about the study of information as a project progresses. The aim of this strategy is to develop the competence and usefulness of project or organization. This strategy help management know things are going wrong. If done correctly can be the best tool for controlling the reading task, and make a suitable base for evaluation. It helps learners to regulate the suitable and important resources that they have, and find the best way to use it well (Slife \& Weaver, 1992). So, monitoring denotes to personal conscious awareness of comprehension and text performance. The ability to involve in periodic self-controlling while reading is a good example for monitoring.

Monitoring strategies occur during reading. Comprehension vocabulary, self-questioning, paraphrasing, and assuming the main idea of each paragraph are the examples of monitoring strategy (Israel, 2007; Pressley, 2002). In monitoring strategy readers distinguish and pay attention to some main evidence or important words, such as however, but, on the other hand, also, in addition and in conclusion. Based on the purpose of the task, they decide which part of the text is more important and lay emphasize on it and ignore some parts that are not important (Hudson, 2007).

In monitoring strategy learners can examine the information as a scheme progresses. In this strategy learners enhance the competence and the value of a project or organization. It can help learners to ease and manage the things that they are going to do. When learners done their task correctly, it is an important tool for better controlling and takes care while reading, and it needs a suitable base for evaluation. This strategy helps learners understand that their available resources are sufficient and suitable, or their abilities are adequate and appropriate. Therefore, monitoring strategy denotes to personal conscious awareness of performance. The capacity to involve in periodic self-controlling while reading is the best example for monitoring (Slife \& Weaver, 1992).

\subsubsection{Evaluation}

Evaluation is defined as assessing the deduction and regulatory processes of an individual's learning. For instance, evaluation includes re-evaluating personal's goals and conclusions.

Evaluation strategy can be summative. It means illustrate learning for a complete project. It can look at everything that student set to do, what they should do, and how they do it. Metacognitive knowledge and regulatory skills such as planning are linked to evaluation. It can help learners to comprehend reading text better (Baker, 1989).

Scholars believed that if learners know when and how use regulatory skills and utilize them as one of the instructional program in the classroom activities can affect their development in their comprehension tests. These three regulator process are very important to motivate learners to regulate their development in reading comprehension (Swanson, 1994).

There is a positive relationship between metacognitive reading strategies awareness and reading comprehension (Ahmadi, 2013). Flavell (1976) believed that self-monitoring and regulation is the most important factor in reading comprehension. These strategies help learners to improve their reading comprehension and encourage readers to read more and comprehend better the written text. 
Evaluating strategies occur after reading. After reading, when learners think, how to apply what they have read to other situation is an example of evaluating strategy. They may identify with the author, a narrative, or main character, and may have a better perspective of the situation in the book than they did at first. So, metacognitive reading strategies are classified into three groups of planning (pre-reading), monitoring (during reading), and evaluating (post-reading) strategies, and each group has a variety of strategies that require readers' metacognitive processing (Slife \& weaver, 1992).

Considering the assumption and regulatory procedures of person's learning is evaluation. For instance, evaluation includes re-evaluating learners' goals and conclusions. Evaluation strategies can be collective that means, illustration learning for final scheme. Evaluation is the relation between real project effects and the decided strategic plans. Evaluation can consider, what learners set out to do, what learners have done, and how they did it. Many investigators believed that metacognitive knowledge and regulatory skills like, planning are connected to evaluation, which can ease reading comprehension (Baker 1989).

One of the best program in classroom activities that can affect their comprehension is that they know when and how use regulatory skills and utilize them. Learners can control their improvement in reading comprehension with regulators process such as planning, monitoring, and evaluation (Swanson, 1994).

\section{Reading Comprehension}

Reading is an appropriate system of learning that educational society need. The students can improve their knowledge with improving reading ability. The learners' goal of reading is understanding the text literally and getting inferences (Othman, 2010).

The comprehension of learners in all tasks of language learning is related to reading comprehension abilities. Some tasks like using textbooks, writing tasks, acquiring vocabulary, grammar, and language learning programs. (Mikulecky, 2008). Anderson claimed that reading is one of the most important skills for English learners. The learners can confirm their success in learning (2003, P2). Reading comprehension is an intricate process that needs a dynamic thinking in mind to understand and realize what has been read (Sheng, 2000).

It is the purpose of reading that determines our reason to teach and care about it. Reading ability can be defined as the efficiency "to draw meaning from the printed page and interpret this information appropriately" (Grabe \& Stoller, 2002, p. 9). Reading comprehension can be defined as understanding written material that is read, or the process of constructing meaning from written material.

Learners of a second or foreign language may hardly ever find opportunities to converse with native speakers orally, but they can read various texts in different topics with changeable degrees of detail and complexity. Nowadays, technology provides the scientific findings materialize in different written texts. Thus, the need for reading and getting information from these passages is essential (Rajabi, 2009).

As Bernhard stated, reading comprehension was the most important and long-lasting aspects of the second language learning (1991). Rivers (1981,p.259) proposed that reading is one of the most important activities in any language class, not only as a source of information and an 
enjoyable activity, but also as a means of strengthening and broadening one's knowledge of the language.

Reading is an "interactive" process between a reader and a passage that leads to fluent reading (Alyousef, 2005). Understanding of the meaning occur through the interaction between the reader and the text.

Some researchers believe that reading performance is considered as the product of decoding and listening comprehension. It can be considered as a useful technique for improving students' success in receiving valuable knowledge from the text (Mayer, 2003, p. 34). As defined by Partnership reading comprehension is perceiving a text that is read, or the process of "constructing meaning" from a text. Comprehension is a "construction process" since it involves all of the factors of the reading process working together while a text is read to produce an image of the text in the reader's mind (2005).

Anderson suggested that, reading is an active, fluent process which involves the reader and the reading material in building meaning (1999, p. 1, as cited in Ertan \& Razi, 2009). Perfetti, Landi, and Oakhill claimed that comprehension is perceptual image of the text message which has three levels: (a) word level (lexical processes), (b) sentence level (syntactic processes), and (c) text level (2004).

Pressley believed that reading is a hierarchy of skills. The learner should pass each stage to enter the next one, this process begin with learning letters, sounds, words, and sentences. So, these stages are related to each other and for understanding the text learner should pass the stages (2000).

\subsection{Types of Reading}

\subsubsection{Extensive Reading}

"There are some different definitions of the term extensive reading" (Hedge, 2003, p. 202). Some scholars believe that extensive reading use describes skimming and scanning activities, others companion it to quantity of material. Hafiz and Tudor stated that, The pedagogical value attributed to extensive reading is based on the assumption that exposing learners to large quantities of meaningful and interesting L2 material will, in the long run, produce a beneficial effect on the learners' command of the L2 (1989, p. 5).

Hedge believed that, extensive reading is based on students' motivation and school resources. A professional teacher can select the best aids or materials for learners (2003). He also stated that since extensive reading helps in developing reading ability, the teachers should pay more attention to it, and use it to improve learners reading comprehension (ibid, p. 218). Hedge (2003) argued that, "it is difficult to know exactly how any learner will actually use the input available" (p. 204). However, "it can be seen as an input enabling activity" (ibid).

\subsubsection{Intensive Reading}

In intensive (or creative) reading, learners read the passage to find the meaning and to be familiar with writing mechanisms. Hedge argued that it is "only through more extensive reading that learners can gain substantial practice in operating these strategies more independently on a range of materials." (ibid, p. 202) These strategies can be either text-related or learner-related: the former includes an awareness of text organization, while the latter includes strategies like linguistic, schematic, and metacognitive strategies. (Hafiz and Tudor, 1989, p.5). $\mu$ 
After a short review on different types of reading comprehension, in this section, I am going to explain about the importance of teaching reading that are influential in interpreting the message which the writer tries to convey, and the role of teacher to use the best method to improve learners' reading abilities.

\subsubsection{The importance of teaching reading}

New modern reading tasks, unlike the traditional materials, consist of three-phase procedures: pre-, while-, and post- reading stages. Pre-reading task can facilitate comprehension.so, this stage is too important for learners to improve their reading abilities. Unfortunately some teachers do not pay attention to this stage (pre-reading procedures) and they pretend that the time is not enough. In fact, pre-reading tasks persuade students before the actual reading tasks place. For instance, teachers can ask learners questions that provoke their attention while reviewing the text (Zhang, 1993, p. 5).

Drucker suggested some methods that teachers can use before reading a text: the students should read the passage that is familiar to them.) The teacher offers a discussion question that will involve the students and, after that, make a summary of that part. Name the choice, introduce the characters, and define the plot (up to, but not including, the climax). Last, direct the students to read the story and look for specific information (2003, p. 23).

Hedge (2003) stated that any reading element of an English language course may consist of a set of learning aims for:

a) Improve the learners' abilities in wide range of texts in English. This is the long-term goal that teachers pursue to achieve in EFL/ESL classroom.

b) Constructing an information of language that can ease reading ability.

c) Constructing and simplifying the main part of the knowledge.

d) The ability to adjust the reading style according to reading purpose (i.e. skimming, scanning).

e) Increasing a consciousness of the structure of written texts in English.

f) Taking a critical posture to the contents of the texts.

Reading strategies is the most important issue that lecturers and researches pay attention to study about it, because they want to find the way to increase students' comprehension.

Hedge believed that it is the teacher's duties to motivate students by choosing the appropriate materials, especially for younger learners. He studied about several features of intrinsic motivation. He mentioned, "Meaningful conceptual content in reading instruction increases motivation for reading and text comprehension." The second motivation-supporting practice showed that students who had a chance to choose the text, performed the tasks better than those with no chance. The third practice was using interesting texts. He concluded, teachers should use interesting texts and consider variety of topics (2003).

Carrell (1989) steered a study on two metacognitive strategies, semantic mapping (SM) and the experience-text-relationship (ETR) method, to study their effect on SL reading (p.647). Carrell argued that besides "being effective for vocabulary development, semantic mapping has proved to be a good alternative to traditional pre-reading and post-reading activities" (p. 651).

Alyousef stated, "Most contemporary reading tasks include pre-reading activities. Therefore, I believe pre-reading activities can be followed by SM strategy since the former aim at increasing learners' motivation". While teachers use semantic mapping as a tool to evaluate students' plan, 
the experience text-relationship (ETR) method emphasizes reading comprehension, for meaning (2005).

In short, the teachers and lecturers use some particular strategies to enhance learners reading abilities. In the next section I am going to convey some definitions of metacognitive strategy and different dimension of it, and deliberate about the effect of metacognitive strategies on reading proficiency.

\section{Conclusion}

Studies on reading strategies have focused on metacognition, emphasizing how readers control, monitor, and assess the reading process.

Phakiti reported," the metacognitive reading strategies used by the EFL students and the results suggested that the students who reported using significantly higher metacognitive strategies showed better reading test performance" (2003).

Metacognition can increase metacognitive awareness of what learner know and how understood it, and they can regulate the use of strategies in different facts. This is the continuum and changing awareness. Skillful readers utilize one or more strategies to understand the text. Learners use different strategies actively and choose the best one to develop their comprehension (Kuhn, 2000).

Metacognitive strategies in reading process, these strategies aid them to be better self-regulated learners that it means they know how to plan and monitor their competence, evaluate their performance and help them to raise their responsibility for the learning and they were satisfy themselves that improved their reading comprehension. These students know how to cope with their problems and tasks because they knew what they do, read and understand (Birjandi, 2006). Finding in present study approved the argument made by Goh stated that each learner possesses some knowledge about reading in another language. Sharing this valuable resource helps everyone to benefit, and may help the whole class to make faster progress. When students become fully aware of the various aspects of second language reading, they will be well placed to become more autonomous readers (1997).

Metacognition is an advanced order thinking process for active control over cognitive processes. Learners with metacognitive awareness perform better than the others. Students are able to regulate their planning, monitoring, and evaluate their learning procedures. So metacognitive instruction has effect on learners' performance (Gama, 2004).

Metacognitive awareness training makes readers better at processing and storing information. While students are familiar with reading strategies and explain how and where use them, can help them to have better reading comprehension.

The metacognitive instruction has increased the awareness of reading strategies and has affected on reading through reading and through strategy use. Activating reading strategy use in the process of communication helps readers-speakers to regulate both input processing and output production (Katal and Rahimi, 2013, P.80, 81).

The learners should improve metacognitive awareness in second language reading and teachers could help them. Li noted "Metacognitive knowledge can be effective only if it is applied into practice" (2013, p.505). Thus, as Li noted "they can consciously use appropriate strategies". 
Metacognitive reading strategy is an effective factor that fostering reading comprehension among readers (Salataki \& Akyel, 2002).

"It is essential for ESL/EFL teachers to teach metacognitive strategies explicitly, provide diverse methods, and facilitate students' learning to help them become independent practitioners. Exploring the role that both first and second languages play in developing students' metacognitive strategies remains a fertile ground for further research" (Iwai 2011). It is important to help students and learners why, when, and how they use strategies in different situations. It is necessary for teachers to provide learners with opportunities to practice the new strategies that they can use these strategies correctly and usefully.

Nowadays, learning strategy research is popular and even practical. But most learning strategies are limited to general strategies, particularly cognitive strategies. The metacognitive is the new field that is interesting for some researchers. Recently, metacognition has been found to be effective in second language teaching and learning. Developing metacognitive awareness in learners may also lead to the development of stronger cognitive skills and much deeper processing. In fact, metacognitive strategy is useful in daily life (Anderson, 2000).

Over the last 35 years, scholars have proposed many definitions for the word metacognition, or "thinking about thinking". A latest definition of metacognition refers to "one's knowledge and beliefs about one's own cognitive processes and one's resulting attempts to regulate those cognitive processes to maximize learning and memory". Furthermore, metacognition plays an important role in our everyday life. It can be used for, communication, reading comprehension, language acquisition, social cognition, attention, self-control, memory, self-instruction, writing, problem solving, and personality development. Metacognition involves knowledge and regulation of one's thinking processes. So, Metacognition as a person's knowledge and ability can be improved with personal experience and schooling (Ayuub\& Ahmad Khan, 2013).

The present study was investigated to explore the effectiveness of metacognitive strategies on the reading comprehension ability of the EFL students. According to some researchers metacognitive strategies have strong effect on reading performance. There is a positive relationship between metacognitive reading strategies awareness and reading comprehension (Ahmadi, 2013). "There is a strong link between metacognitive reading strategy awareness and reading comprehension. So talented readers use different metacognitive reading strategies while reading and less talented readers do not utilize these strategies while reading and cannot improve their reading performance" (Koda, 2005, Cohen, 2003; Tang \& Moore, 1992).

The metacognitive strategies that were explored in this study include planning, monitoring, and evaluating (Israel, 2007; Pressley \& Afflerbach, 1995). Before reading learners can use planning strategies. For instance, learners can use background knowledge to get prepared for reading (Almasi, 2003; Israel, 2007). Also, learners can utilize previewing a title, picture, illustration, heading, or subheading to understand the outline of the script. They can preview the overall information in the text and the structure (Almasi, 2003; Paris, Wasik, \& Turner, 1991). Students can find that their reading material has a specific text structure, such as compare and contrast, cause and effect and question and answer. So, set the goal for reading can be classified as a planning strategy (Paris et al., 1991; Pressley, 2002). ). In monitoring strategy readers distinguish and pay attention to some main evidence or important words, such as however, but, on the other 
hand, also, in addition and in conclusion. Based on the purpose of the task, they decide which part of the text is more important and lay emphasize on it and ignore some parts that are not important (Hudson, 2007). Evaluation can consider, what learners set out to do, what learners have done, and how they did it. Many investigators believed that metacognitive knowledge and regulatory skills like, planning are connected to evaluation, which can ease reading comprehension (Baker 1989).

One of the best program in classroom activities that can affect their comprehension is that they know when and how use regulatory skills and utilize them. Learners can control their improvement in reading comprehension with regulators process such as planning, monitoring, and evaluation (Swanson, 1994).

Through metacognitive strategies use, the students learned how to read effectively, how to work out what reading, how to work well in cooperation with others, how to cope the accomplishment of tasks, how to use what they know in new and unpredictable situations, and so on. The design of the test was based on a theoretical model of metacognition, a construct that refer to thinking about one's thinking or human ability to be conscious of one's mental process (Flavell, 1979; Nelson, 1996). The results of the three instruments of metacognitive assessment displayed that experimental group corroborated a higher level of metacognitive strategies use in their reading comprehension comparing to the control group.

\section{References}

Ahiya, p. (1993). Learning to Read effectively and efficiently. New Delhi: Sterling.

Ahmadi, M. R. (2013). The Important of Metacognition Reading Strategy Awareness in Reading Comprehension. Canadian center of Science and Education, 6, 235.

Almasi, J. F. (2003). Teaching strategic process in reading. New York, NY: The Guilford Press. Alyousef, H. S. (2005). Teaching reading comprehension to ESL/EFL learners. The Reading Matrix, 5(2).

Anderson, N.J. (2000). Assessing reading. Cambridge: Cambridge University Press.

Anderson, N. J. (1999). Exploring second language reading. Boston, MA: Heinle \& Heinle.

Ayuub, F. Ahmad Khan, S. (2013). Metacognition Reading Strategies in relationship with scholastic achievement in science of IX Standard Students of English Medium School in Aurangabad city. Mier Journal of Educational Studies, Trends \& practices, 3 (1), 119-129.

Baker, L. (1989). Metacognition, comprehension monitoring, and the adult reader. Educ. Psychol. Rev., 1, 3-38.

Baker, L., \& Brown, A. L. (1984). Metacognitive skills and reading. In P. D. Pearson (Ed.), Handbook of reading research (pp. 353-394). New York: Longman.

Bernhardt, E. (1991). Reading development in a second language. New York, NY: Ablex. 
Bulletin de la Société Royale des Sciences de Liège, Vol. 86, special issue, p. 220 - 233

Birjandi. P. (2006). Setting- based Metacognitive Strategy Use: A Qualitative and Quantitative Examination. 40-87.

Brown, A. L. (1980). Metacognitive development and reading. In R. J. Spiro, B. C. Bruce, \& W.

F. Brewer (Eds.), Theoretical issues in reading comprehension (pp. 453-481). Hillsdale, NJ: Lawrence Erlbaum Associates, Inc.

Butler,D. L., \& Winnie,P. H. (1998). Feedback and self-regulated learning: A theoretical synthesis. Review of Educational Research, 65, 245-281.

Carrell, P. L., Gajdusek, L. \& Wise, T. (1998). Metacognition and EFL/ESL reading. Instructional Science, 26, 97-112.

Carrel, P. L. (1989). Metacognitive awareness and second language reading. Modern language journal, 73, 121-149.

Cohen, A. (1998). Strategies in Learning and using a Second Language. London: Longman.

Erten, I. H., Razı, S., \& Mart, C. O. (2009). The effects of cultural familiarity on reading comprehension. Reading in a Foreign Language, 21(1), 60-77.

Flavell, J. H. (1979). Metacognition and cognitive monitoring: A new area of cognitive developmental inquiry. American Psychologist, 34(10), 906-911.

Gama, C. A. (2004). Integrating Metacognition Instruction in Interactive Learning Environments. Dissertation Doctor of Philosophy. University of Sussex. 2004 9-56, 61-64.

Goh, C. (1997). Metacognitive awareness and second language listeners. ELT Journal Volume 51(4) October 1997. Oxford University Press. 361-369.

Grabe, W., \& Stoller, L. F. (2002). Teaching and researching reading. Harlow, England: Pearson Education.

Hafiz, F. M. \& Tudor, Ian. (1989). Extensive reading and the development of language skills. ELT Journal, 43(1), 4-13.

Hedge, T. (2003). Teaching \& learning in the language classroom. UK: OUP.

Heilman, A.W. (1998). Principles and Practices of Teaching Reading. New Jersey: PrenticeHall.

Hudson, T. (2007). Teaching second language reading. Oxford: Oxford University Press.

Israel, S. E. (2007). Using metacognitive assessments to create individualized reading instruction. Newark, DE: International Reading Association. 
Bulletin de la Société Royale des Sciences de Liège, Vol. 86, special issue, p. 220 - 233

Iwai, Y. (2011). The Effect of Metacognitive Reading Strategies: Pedagogical Implications for EFL/ESL Teachers. The Reading Matrix, 11(2).

Katal, M., \& Rahimi, M. (2013). The Impact of Metacognitive Instruction on EFL Learners' Listening Comprehension and Oral Language Proficiency. The Journal of Teaching Language Skills (JTLS), 5 (2), 2013, Ser. 71/4. ISSN: 2008-8191. pp. 69-90.

Kerlinger, F.N. (1986). Foundation to Behavioral Research Methods. California: Wadesworth.

Koda, K. (2005). Insights into second language reading: A cross-linguistic approach. Cambridge: Cambridge University Press.

Kuhn, D. (2000). Metacognitive development. Current Directions in Psychological Science, 9(5), 178-181.

Mayer, R. (2003). Learning and instruction. Upper Saddle River, New Jersey: Pearson Education.

McCormick, C. B. (2003). Metacognition and learning. In I. B. Weiner (Series Ed.), W. M. Reynolds \& G. E. Miller (Vol. Eds.), Handbook of psychology: Educational psychology (Vol. 7, pp. 79-102). Hoboken, NJ: John Wiley \& Sons, Inc.

Mikulecky, P. S. (2008). Teaching reading in a second language .Pearson Education, 0-13503146-X.

Miller, P. H. (1985). Metacognition and Attention, In Forrest-Pressley, D. L., McKinnon, E. G., \& Waller, T. G. (Eds.), Metacognition, Cognition, and Human Performance (pp. 181-221). Academic Press, New York.

Othman,Y. (2010). Application of metacognition strategies and awareness when reading texts. The International Journal of Learning, 17(3), 457-472.

Paris, S., Wasik, B. A., \& Turner, J. C. (1991). The development of strategic readers. In R. Barr, M. L. Kamil, P. B. Mosenthal, \& D. Pearson (Eds.), Handbook of Reading Research (vol. 2, pp. 609-640). Mahwah, NJ: Lawrence Erlbaum.

"Partnership for Reading." Retrieved from http://www.nifl.gov/partnershipforreading/.

Perfetti, C. A., Landi, N. \& Oakhill,J. (2004). The acquisition of reading comprehension skill. Retrieved from http://www.haskins.yale.edu/Teagle/PerfettiEtAl.pdf

Pressley, M. (2002). Metacognition and self-regulated comprehension. In A. E. Farstrup \& S. J. Samuels (Eds.), what research has to say about reading instruction (pp. 291-309). Newark, DE: International Reading Association

Pressley, M., \& Afflerbach, P. (1995). Verbal protocols of reading: The nature of constructively responsive reading. Hillsdale NJ: Erlbaum. 
Bulletin de la Société Royale des Sciences de Liège, Vol. 86, special issue, p. 220 - 233

Pressley, M. (2000). Comprehension instruction: What works? Retrieved from http://www.Idonline.org/article/68?theme=print

Rajabi, P. (2009). Cultural Orientation and reading comprehension models: The case of Iranian rural and urban students. Novitas-ROYAL, 3(1), 75-82.

Rivers, W. M. (1981). Teaching foreign-language skills (2nd ed). Chicago: University of Chicago Press.

Salataki, R., \& Akyel, A. (2002). Possible effects of strategy instruction on L1 and L2 reading. Reading in a Foreign Language, 14, 1-17.

Sheng, H. J. (2000). A cognitive model for teaching reading comprehension.English Teaching Forum, 38(4), 12-15.

Shih, M. (1992). Beyond comprehension exercises in the ESL academic reading class. TESOL Quarterly, 26, 289-318.

Silberstein S. (1994).Techniques and Resources in Teaching Reading. New York: Oxford University Press.

Slife, B. D., \& Weaver, C. A. (1992). Depression, cognitive skill, and metacognitive skill in problem solving. Cognit. Emotion, 6, 1-22.

Stone, V. E. (2000). Frontal lobe contributions to theory of mind. Journal of cognitive neuroscience.

Tang, W. N., \& Moore, D. W. (1992). Effects of cognitive and metacognitive pre-reading activities on the reading comprehension of ESL learners. Educational Psychology, 12(3/4), 315331.

Zare-ee, A. (2008). The relationship between cognitive and meta-cognitive strategy use and EFL reading achievements. Faculty of Foreign Language and Literature, Islamic-Azad University, Roudehen Branch, Tehran, Iran. The first regional conference on English language teaching and literature (ELTL-1).

Zhang, Z. (1993). Literature review on reading strategy research, 1-18. Retrieved Nov 1, 2004 from EDRS database (ED356643). 